\title{
Catenas e detalhamento expedito dos solos da bacia do Riacho do Saco - Serra Talhada/Pernambuco
}

\author{
Jonas Otaviano Praça de Souza*
}

\section{Resumo}

Pesquisas com enfoque geomorfológico e hidrológico necessitam de dados pedológicos para realizarem suas análises. Contudo, uma mesma associação de solo, disponíveis nos mapeamentos em mesoescalas, contém classes de solo que podem apresentam respostas hidrológicas e erosivas distintas, gerando falhas na análise. O presente estudo visou detalhar essas associações localizando cada classe de solo da bacia, utilizando catenas referências para o sertão pernambucano e abordagens do mapeamento digital de solos. Deste modo foi gerado um mapa com a localização detalhada das classes de solo existentes, identificando solos não delimitados no mapeamento básico, como afloramentos rochosos e planossolos. Aumentando o grau de precisão da base de dados de solo, importante, por exemplo, para os estudos hidrológicos e geomorfológicos. A metodologia utilizada se mostrou adequada para a discriminação das classes de solo visando estudos hidrológicos e geomorfológicos.

Palavras-chave: Mapeamento de solos; Catena; Solos do semiárido.

Catenas and swift soil detailing in Saco Watershed -

Serra/Talhada Pernambuco

\begin{abstract}
Geomorphological and hydrological researches need soil information to process your analysis. Nevertheless in one soil

Doutorado em Geografia e Professor pela Universidade Federal de Pernambuco (jonasgeoufpe@yahoo.com.br)
\end{abstract}

Geosul, Florianópolis, v. 28, n. 56, p 163-182, jul./dez. 2013 
SOUZA, O.P. de. Catenas e detalhamento expedito dos solos da bacia do...

association, provided by meso-scales maps, comprehends soil classes that may show distinct hydrological and geomorphological responses, causing analysis miscalculations. This paper aimed to detail these associations setting the boundaries of each soil class in the watershed, using model catenas to Pernambuco drylands and digital soil mapping approaches. Hence, a detailed soil map was generated with each soil boundaries, therefore soil classes which weren't delimited in the basic soil map show up, such as rock outcrop and planosols. Consequently, it increases the soil data accuracy to geomorphological and hydrological studies. The methodology was satisfactory to discern the soil classes focusing the hydrological and geomorphological researches.

Key words: Soil mapping, Soil catena, Semiarid soils.

\section{Introdução}

Um mapeamento das classes de solo numa escala adequada é imprescindível não apenas a pesquisas em pedologia, mas como base para estudos de geomorfologia processual e hidrologia, como, por exemplo, estudos sobre erosão e/ou escoamento superficial. No caso de Pernambuco há, de fácil acesso, o mapeamento dos solos em escala de 1:100.000 cobrindo todo o estado (EMBRAPA, 2001), onde é fornecido as manchas de solo predominante em cada área, como também a porcentagem da associação com outras classes de solo.

Em trabalhos de maior detalhe, como os estudos em pequenas bacias, o nível de detalhe obtido pelo mapeamento de associações de solo na escala 1:100.000 destoam da precisão almejada, sendo necessário um aperfeiçoamento da base de dados espacial pedológica. Contudo, para aprimorar os mapeamentos de solo pelos métodos tradicionais demandam, além da expertise em ciências do solo, tempo e custos altos (CHAGAS, CARVALHO JUNIOR, et al., 2011; ZIADAT, 2007). Deste modo torna-se impossível esse detalhamento para estudos cujo objetivo principal não seja 
SOUZA, O.P. de. Catenas e detalhamento expedito dos solos da bacia do...

pedológico, sendo as informações sobre os solos apenas parte da base de dados necessária para o desenvolvimento do estudo em si, como é o caso, já citado, de estudos hidrológicos; onde, por exemplo, no atual mapeamento há em uma mesma associação de solos há argissolos e afloramento rochosos o que geraria respostas completamente diferentes para o escoamento superficial.

Visando dar celeridade e baratear o processo de mapeamento de solos alguns métodos de mapeamento digitais foram desenvolvidos. Tais mapeamentos digitais apoiam-se em imagens de satélite, para identificação de características ambientais, e modelos digitais de elevação, para a retirada de informações topográficas; como também informações geológicas para que a partir da análise desses dados se possa identificar as classes de solo (CHAGAS, CARVALHO JUNIOR, et al., 2011; SCULL, FRANKLIN, et al., 2003). Há diversos métodos/técnicas para a definição das classes de solo, cada qual utilizando diferentes características, entre elas há o tipo de vegetação, o clima, litologia, elevação, declividade, aspecto, curvatura da encosta, índice topográfico combinado, índice de umidade, direção de fluxo, acumulação de fluxo, distância da drenagem, entre outros (CHAGAS, CARVALHO JUNIOR, et al., 2011; CARDENAS, SOLORIO, et al., 2011; GIASSON, CLARKE, et al., 2006; NANNI, CEZAR, et al., 2010; ZIADAT, 2007; BRUIN e STEIN, 1998; MULDER, BRUIN, et al., 2011; ZIADAT, TAYLOR e BREWER, 2003; BODAGHABADI, SALEHI, et al., 2011). Normalmente as técnicas são empregadas para gerar mapas pedológicos em áreas onde não há informação, ou para aumentar a escala de mapas já existentes, contudo as identificações continuam, geralmente, sendo realizadas em associações de solo, gerando as mesmas questões citadas anteriormente.

Deste modo, a pesquisa em tela busca aplicar um método expedito, baseado nos mapeamentos digitais e dados topográficos, para detalhar a localização de cada classe de solo presente nas associações pedológicas do mapa disponível para a região, baseado 
SOUZA, O.P. de. Catenas e detalhamento expedito dos solos da bacia do...

em catenas representativas para a bacia do Riacho do Saco, Serra Talhada, Pernambuco.

\section{Caracterização ambiental e pedológica da área}

A bacia de drenagem do riacho do Saco está situada nas cabeceiras da bacia do Pajeú, Sertão Central de Pernambuco, entre os municípios de Serra Talhada, Triunfo e Santa Cruz da Baixa Verde, além de algumas cabeceiras de drenagem nos municípios de Manaíra e São José da Princesa, na Paraíba (figura 01, esquerda), perfazendo uma área de $142,5 \mathrm{Km}^{2}$. Regionalmente, a bacia está inserida na Depressão Sertaneja, e suas cabeceiras de drenagem encontram-se sobre a Encosta Meridional do Planalto da Borborema (CORRÊA, TAVARES, et al., 2012). Apresentando uma amplitude altimétrica de cerca de 700 metros entre a foz $(409 \mathrm{~m})$ e as cabeceiras (superior a $1100 \mathrm{~m}$ ), há, basicamente, dois arranjos ambientais distintos (figura 01 direita).

Um arranjo abaixo de 700 metros, mais seco com predominância de caatinga e pecuária extensiva, e um acima dos 900 metros, mais úmido com a presença de floresta subcaducifólia com predominância de policultura e pastagem; além de uma paisagem de transição, com características das duas anteriores, entre 700 metros e 900 metros, ocorrendo, basicamente, pela diferença de umidade que se reflete em outras características da paisagem.

A área em questão apresenta dois mapeamentos de solos, não sobrepostos, em escalas distintas: um na parte pernambucana na escala de 1:100.000 (EMBRAPA, 2001); e na parte paraibana na escala de 1:500.000 (BRASIL, MINISTÉRIO DA AGRICULTURA, 1972), com atualização da nomenclatura para o mapeamento da Paraíba (CAMPOS e QUEIROZ, 2006). A atualização da nomenclatura dos solos de Pernambuco foi realizada a partir das orientações do Sistema Brasileiro de Classificação de Solos (EMBRAPA - CENTRO NACIONAL DE PESQUISAS DE SOLOS, 2006). Apesar dos mapeamentos pedológicos terem sido realizados em escalas diferentes e a partir de metodologias também diferentes, a área paraibana da bacia, 
SOUZA, O.P. de. Catenas e detalhamento expedito dos solos da bacia do...

com menor escala (1:500.000), é ínfima sendo possível utilizar esses dados para elaborar um mapa geral dos solos da bacia (figura 02).
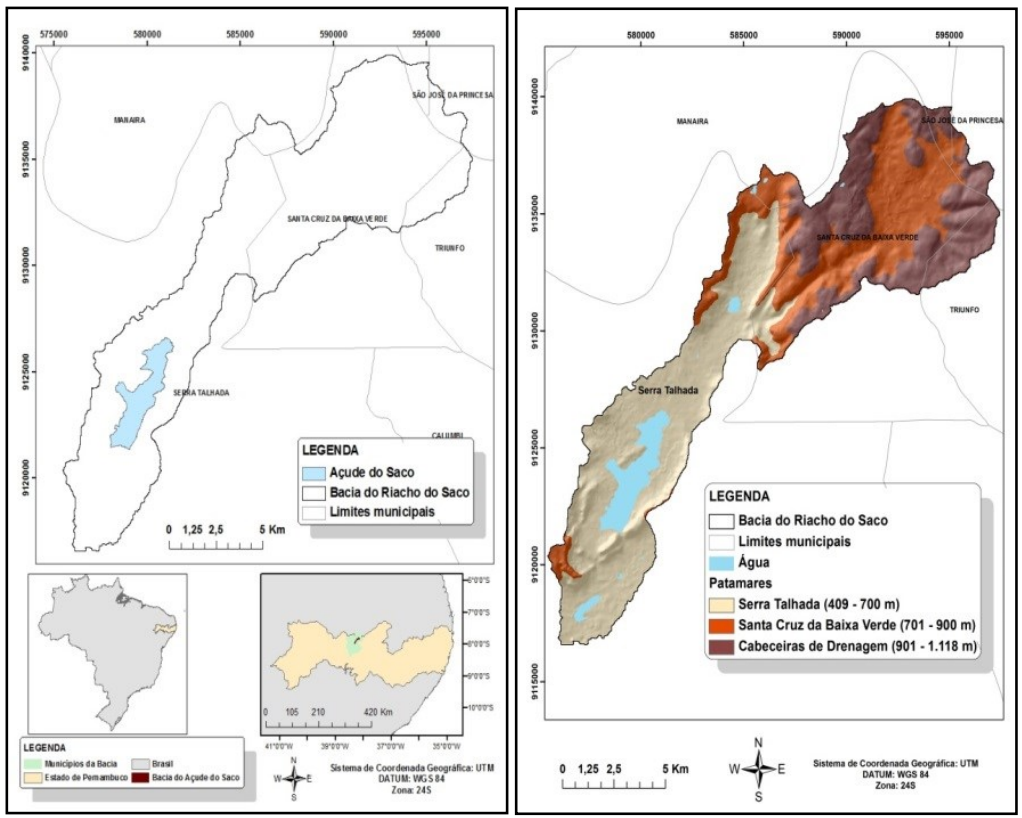

Figura 1: Esquerda - Mapa de localização da bacia do Riacho do Saco. Direita - Patamares da bacia do riacho do Saco.

As classes apresentadas são na realidade o tipo de solo predominante, sendo que eles representam associações entre classes de solos em diferentes proporções, identificadas pelas siglas contidas no mapa. As associações identificadas por EMBRAPA (2001) apresentam as porcentagens de cada classe de solo; ao contrário as identificadas por BRASIL (1972) indica apenas as classes associadas a classe principal. As associações da área da bacia são; dados extraídos de Silva et al (2001) e BRASIL (1972), e adaptadas seguindo as instruções de EMBRAPA (2006). 
SOUZA, O.P. de. Catenas e detalhamento expedito dos solos da bacia do...

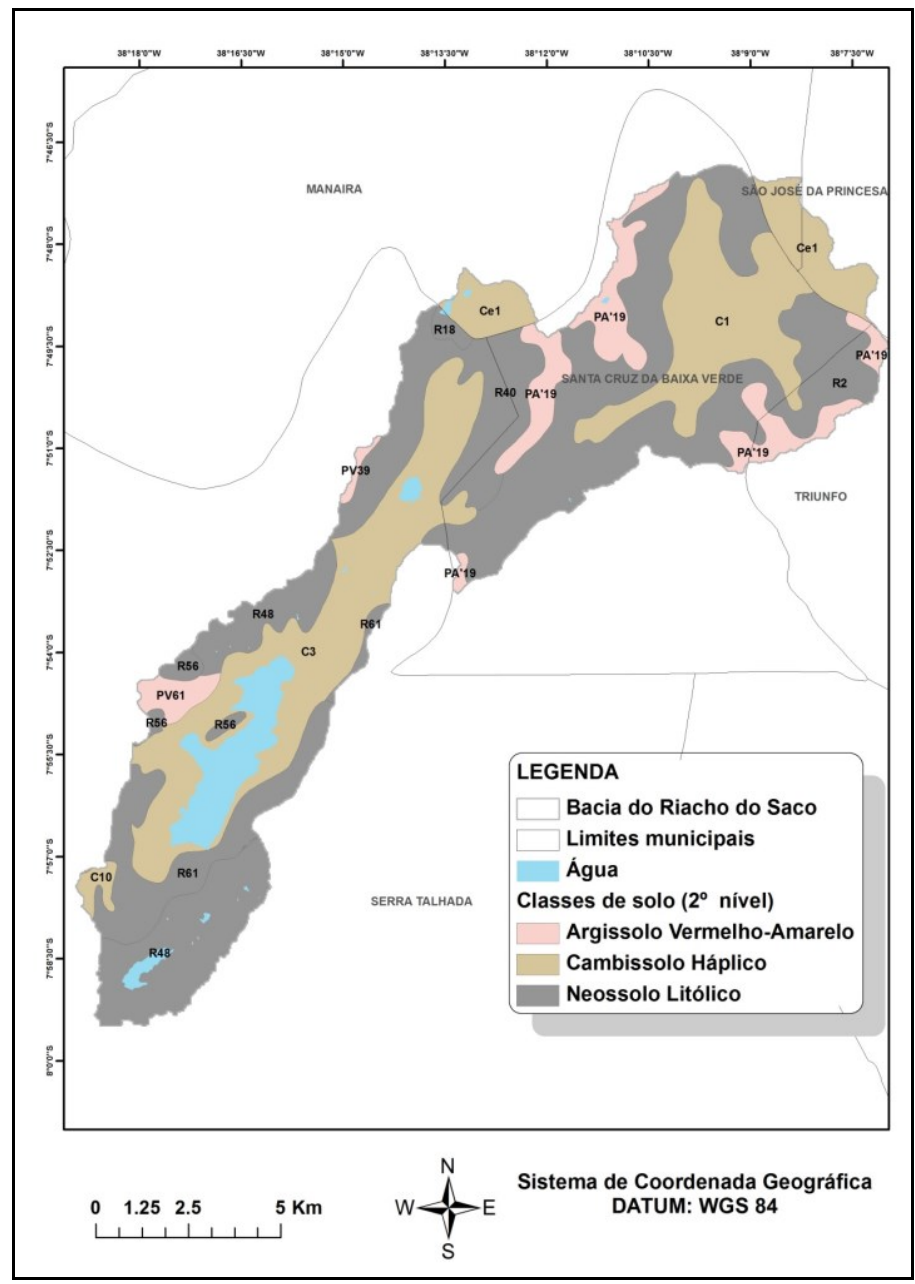

Figura 2: Mapa geral dos solo ( $2^{\circ}$ nível categórico $)$ da bacia do riacho do Saco. Adaptado de Brasil (1972) e Silva et al (2001). 
SOUZA, O.P. de. Catenas e detalhamento expedito dos solos da bacia do...

Catenas para terras secas pernambucanas

$\mathrm{O}$ aprofundamento do estudo da relação solo-relevo no semiárido pernambucano dá-se por estudos recentes (CORRÊA, SOUZA e CAVALCANTI, em prelo) e leva em consideração a distribuição dos solos no semiárido a partir da localização no relevo e da litologia associada. Criou-se, assim, quatro catenas típicas no semiárido pernambucano, três para ambientes de rochas cristalinas e uma para ambientes de rochas sedimentares (CORREAA, SOUZA e CAVALCANTI, em prelo); os autores partiram de uma catena simples, contudo a de maior ocorrência no semiárido nordestino, que é a que representa os pedimentos da depressão sertaneja, e a partir desta identificaram as catenas dos contatos desses pedimentos com outros compartimentos geomorfológicos do semiárido.

A área da bacia do riacho do Saco, por estar entre o pedimento e um maciço residual, estaria representada por três dessas catenas: a catena de pedimento (figura 03), o extremo sul da bacia, a catena do contato entre pedimentos e maciços residuais (figura 04), o patamar intermediário da bacia (patamar de Serra Talhada); e a catena de planaltos em rocha cristalina (figura 05), a porção superior da bacia (patamar de Santa Cruz da Baixa Verde), inclusive os autores usaram o exemplo de Santa Cruz da Baixa Verde para identificar essa catena.

A catena para as áreas pedimentares é a de maior incidência na Depressão Sertaneja pernambucana, como é o caso das áreas classificadas como R 48 no mapa de solos da bacia do riacho do Saco, onde a baixa incidência de chuva impede um maior desenvolvimento dos solos. Luvissolos presentes nas rampas de pedimentos, os Planossolos nas baixadas pertos dos riachos, os Neossolos Litólicos e afloramentos de rocha nos topos dos interflúvios e cristas/escarpas isoladas. 
SOUZA, O.P. de. Catenas e detalhamento expedito dos solos da bacia do...

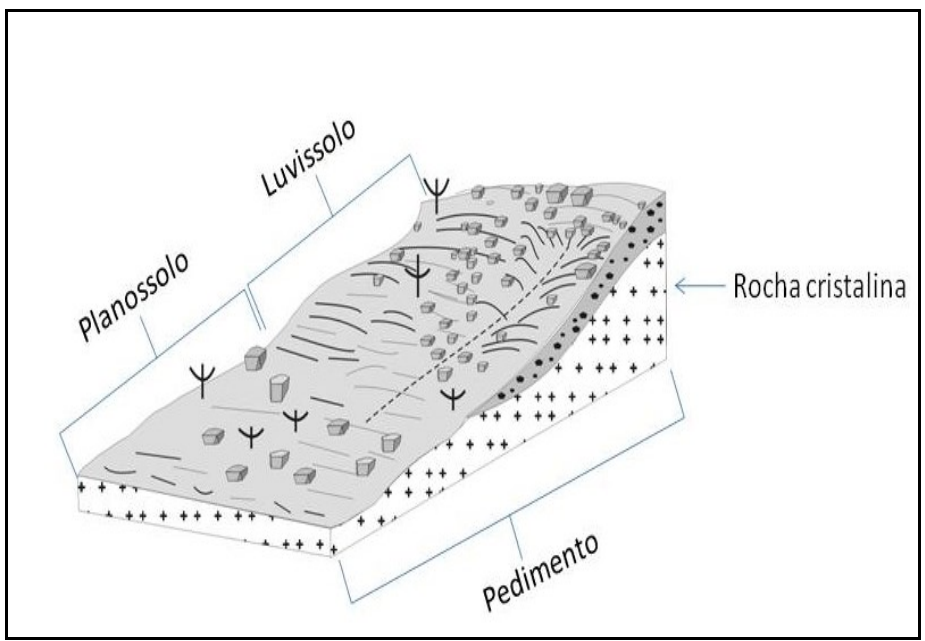

Figura 3: Catena típica de áreas com vastos pedimentos na depressão sertaneja. Exemplo obtido na localidade do Amaro, município de Buíque, Pernambuco. Fonte: CORRÊA, SOUZA e CAVALCANTI, em prelo.

Analisando a catena do encontro do pedimento com os maciços residuais, observa-se a resposta dessa distribuição no mapa de solos da bacia, na área de Serra Talhada, a partir das associações dos solos como a C3 e a PV61. Com o início da catena próximo dos cursos fluviais com a presença de Planossolos, os Luvissolos nas rampas de baixa declividade; e com o contato com os maciços e o aumento da declividade, inicia-se uma associação de cambissolos e argissolos (normalmente relacionado com uma mudança de volume de precipitação, de origem espacial ou temporal). Contudo com o aumento da declividade há um incremento na remoção do solo, dificultando a pedogênese e assim favorecendo a gênese dos neossolos (litólicos e regolíticos) e dos afloramentos rochosos, associação R61. A distribuição da associação dos solos no caso do encontro com os maciços vai estar 
SOUZA, O.P. de. Catenas e detalhamento expedito dos solos da bacia do...

relacionada com a estabilidade de cada vertente, e sua taxa de morfogênese/pedogênese.

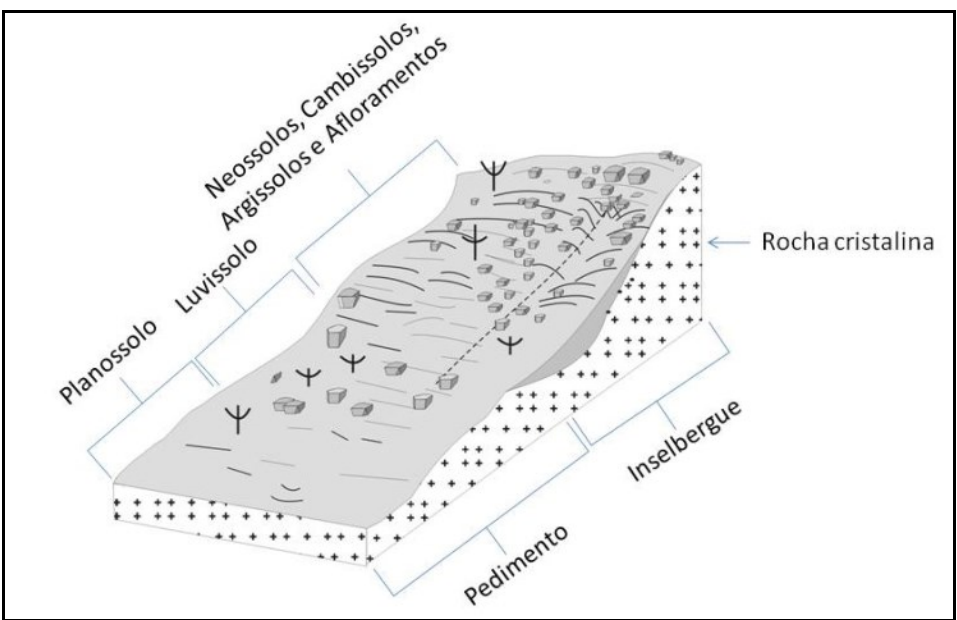

Figura 4: Catena típica do contato entre pedimentos e maciços residuais na depressão sertaneja. Exemplo obtido na Serra do Poço, município de Poço das Trincheiras, Alagoas. Fonte: CORREA, SOUZA e CAVALCANTI, em prelo.

Por ultimo a catena para os compartimentos elevados em rocha cristalina apresenta uma diferenciação dos controles litológicos e climáticos (com a diminuição da temperatura e o aumento da precipitação) modificando a pedogênese, possibilitando a gênese de solos mais desenvolvidos como Latossolos e Argissolos. Contudo a relação com a estabilidade das encostas leva a uma associação dos solos mais profundos com solos menos profundos, Cambissolos e Neossolos.

$\mathrm{O}$ aumento da presença de Argissolos no patamar de Santa Cruz da Baixa Verde demonstrada no mapa de solos é resultado na mudança desses controles, como também do retrabalhamento dos colúvios. Nas áreas de acumulação de colúvio, nas baixas encostas, há a associação dos Argissolos e Cambissolos, representada no mapa 
SOUZA, O.P. de. Catenas e detalhamento expedito dos solos da bacia do...

de solos pela unidade de solos "C1". Enquanto que nas áreas com vertentes de maior instabilidade há a disseminação dos Neossolos, exemplo da unidade de solo "R2". Nas áreas mais altas, onde a uma diminuição da declividade há a presença dos Argissolos em associação com os Neossolos e Afloramentos Rochosos (por se encontrar nas áreas somitais), a unidade de solo PA' 19 é um exemplo claro dessa relação solo/relevo. Ao mesmo tempo, a presença de uma área plana e alagadiça possibilitou a formação de solos relacionadas com forte presença de água, tal como os Gleissolo Háplico e os Neossolos Flúvicos, associação C1.

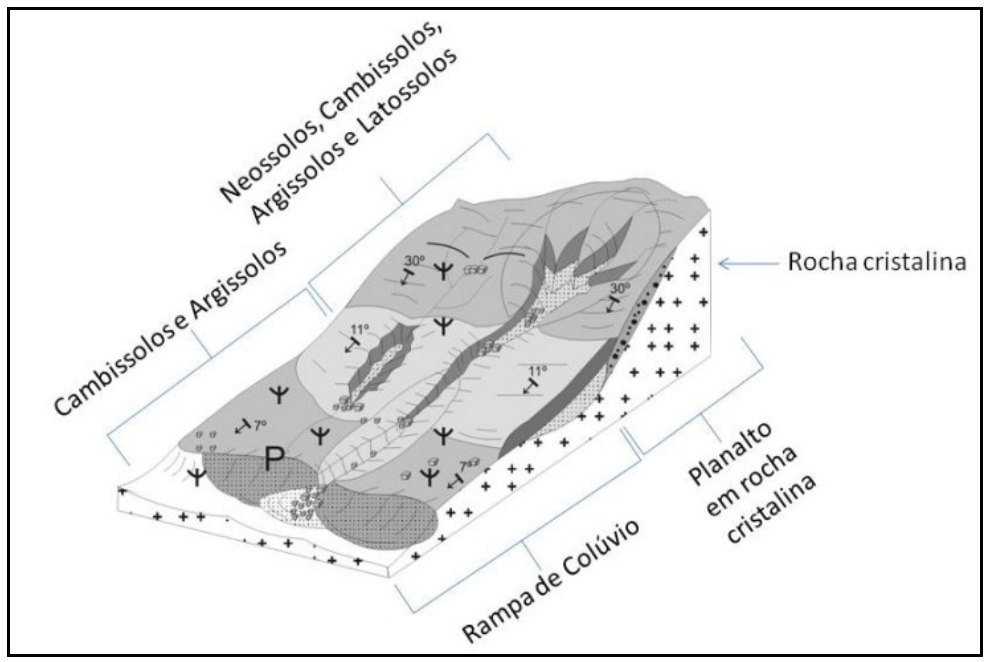

Figura 5: Catena típica de planaltos em rocha cristalina. Exemplo obtido no município de Santa Cruz da Baixa Verde, Pernambuco. Fonte: CORREAA, SOUZA e CAVALCANTI, Em prelo.

Betard, Peulvast e Sales (2007) ao avaliar as características morfopedológicas do Maciço do Baturite-CE, região ambientalmente semelhante ao maciço da Baixa Verde, observaram resultados para as relações solo-relevo semelhantes as 
SOUZA, O.P. de. Catenas e detalhamento expedito dos solos da bacia do...

três catenas em rocha cristalina, mostradas acima (BETARD, PEULVAST e SALES, 2007).

\section{Materiais e métodos}

A identificação dos solos partirá do mapa pedológico existente para a área na escala de 1:100.000, e uma pequena área na escala de 1:500.000, que apresenta associações de solos, e utilizará técnicas de mapeamento digital como fonte secundária de mapeamento visando subdividir as associações de solos baseado nas catenas apresentadas anteriormente. Essa subdivisão levará em consideração a distribuição dos solos na região a partir de atributos topográficos, como declividade, elevação e distância/influência da rede de drenagem (BRUIN e STEIN, 1998; IPPOLITI, COSTA, et al., 2005), o que pode ser feito a partir da utilização de modelos digitais de elevação (ZIADAT, TAYLOR e BREWER, 2003). Por exemplo, em uma determinada zona que teve sua associação de solos identificada, os solos localizados nas áreas de maior declividade são os menos espessos do grupo mapeado, por sofrer constante rejuvenescimento por erosão, entre os fatores que influenciam a distribuição a declividade se apresenta como fator preponderante (CHAGAS, CARVALHO JUNIOR, et al., 2011), como também a distância para a rede de drenagem. Quanto mais próxima à rede de drenagem maior a influência da água na formação do solo, esses dois elementos vão controlar a redistribuição de água e sedimento/solo na paisagem (VALLEJO, CLAESSENS, et al., 2008; BODAGHABADI, SALEHI, et al., 2011).

Com a combinação das informações obtidas pelos levantamentos dos solos da área, resumida no mapa de solos, e levando em consideração a relação solo/relevo, é possível realizar uma aproximação das informações pedológicas a escalas mais detalhadas, como é o caso da atual pesquisa. Saindo das 13 associações de solos, respeitando as porcentagens definidas, e 
SOUZA, O.P. de. Catenas e detalhamento expedito dos solos da bacia do...

chegando à distribuição aproximada das 11 classes $\left(2^{\mathrm{a}}\right.$ ordem) de solos existentes na bacia.

Para tanto foi utilizado dados do projeto ASTER-GDEM 2, disponível gratuitamente, com precisão espacial de 30m. Os dados foram processados a partir do módulo Hidrology, para identificar a área acumulada e a distância para o canal de cada ponto, informações relativas à influência da água na formação do solo, e o módulo Surface, para identificar a declividade de cada ponto, relativa à remobilização e remoção do solo, ambos os módulos estão contidos na extensão Spatial Analyst Tools do Arcgis 10.1, disponível na Auckland University, Auckland, Nova Zelândia. Baseado nessas informações cada associação do solo foi dividida a partir das características formadoras de cada tipo de solo e da proporção definida de cada associação.

\section{Resultados e discussões}

Seguindo as catenas mostradas acima e analisando as relações de declividade, localização na encosta e presença de água, foi possível separar cada classe das associações de solo e localizálos, respeitando as porcentagens discriminadas. Deste modo, foi elaborado o mapa das classes de solo da bacia do Riacho do Saco, com cada classe localizada separadamente. Contudo, cinco delimitações continuaram apresentando associações de solo, pois dentro da base inicial não havia a separação percentual entre elas; são elas: associações de argissolos (2), argissolos com cambissolo (1), gleissolo com neossolo flúvico (1) e associação de planossolos (1). 
SOUZA, O.P. de. Catenas e detalhamento expedito dos solos da bacia do...

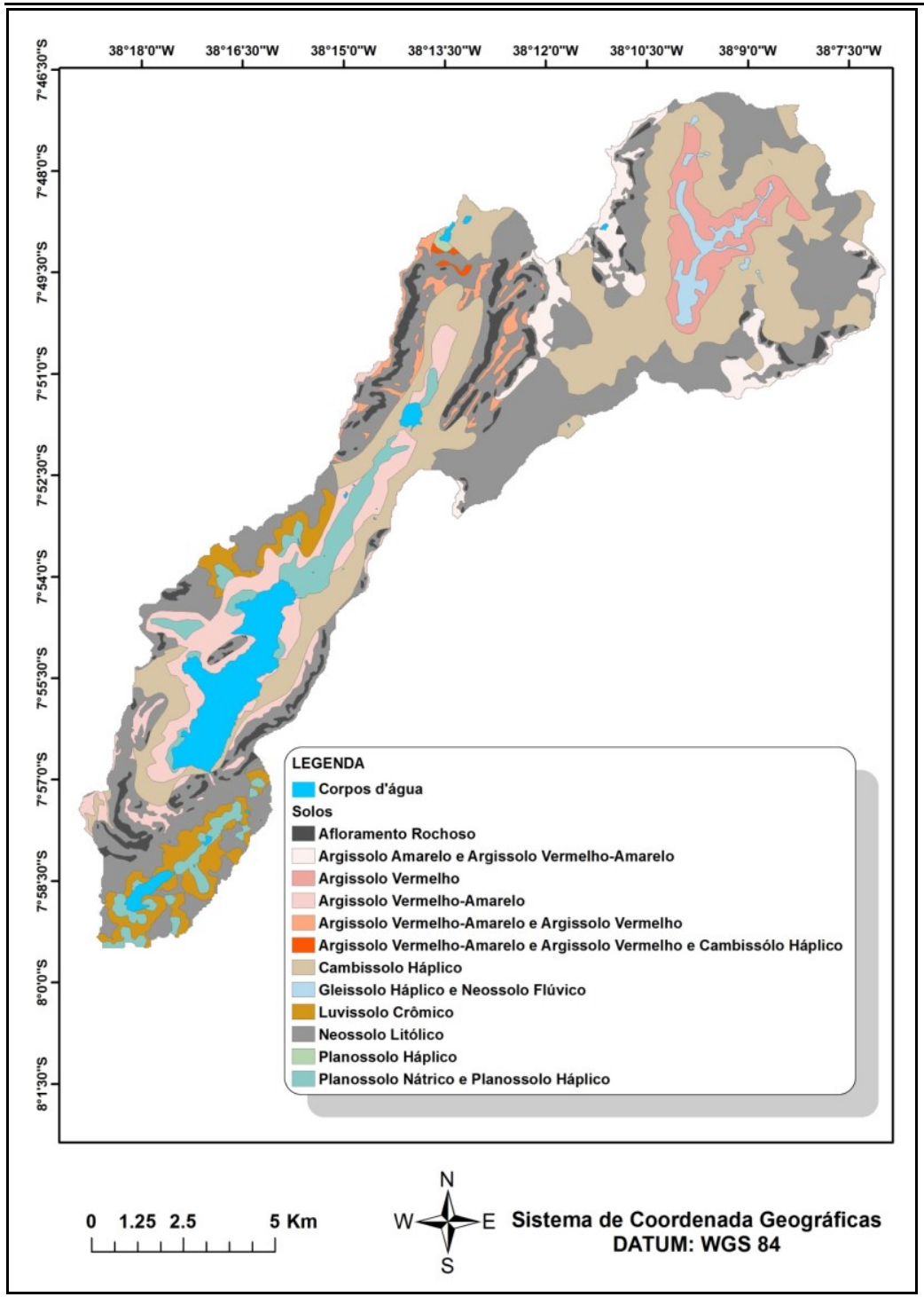

Figura 6: Mapa detalhada das classes de solo da bacia do Riacho do Saco 
SOUZA, O.P. de. Catenas e detalhamento expedito dos solos da bacia do...

Os afloramentos rochosos foram delimitados nas áreas com maior declividade nas associações que eles ocorriam (PA'19, PV39, R40, R56 e R61) sendo de fácil separação. Os neossolos litólicos (Ce 1, C10, PA'19, PV39, PV61, R2, R18, R40, R48, R56 e R61) estão relacionados tanto com um valor mais alto de declividade, o que favorece a retirada do material e prejudica a maturação do solo, quanto com a localização em encostas com declividade homogênea, onde normalmente localiza-se na parte superior da encosta. Os planossolos (C3, PV61, R18 e R48) foram delimitados nas áreas de baixa declividade ou planas, na base da encosta, adjacentes aos canais e normalmente com a possibilidade de inundações ocasionais. Já o gleissolo/neossolo flúvico (C1) será encontrado nas áreas planas e depressões nas planícies de inundação onde há a presença de alagados em grande parte do ano.

Os luvissolos crômicos estarão distribuídos na bacia apenas na associação R48, a qual é descrita na catena referência para a Depressão Sertaneja, deste modo ele foi delimitado na média encosta. Os cambissolos (Ce1, C1, C3, C10, R2 e R18) podem ser identificados por ser um solo de transição, quando associados com os neossolos litólicos apresentam uma menor declividade e localizam-se na média e/ou baixa encosta. Já quando estão associados com os argissolos localizam-se em áreas mais instáveis que os argissolos, ou seja, com maior declividade, estando, normalmente em posição acima na encosta. Por fim, os argissolos (C1, C10, PA'19, PV39, PV61, R18, R40, R61) por serem os solos mais desenvolvidos encontrados na bacia, localizam-se em áreas mais estáveis de menor declividade, normalmente, na média ou baixa encosta, o que vai depender de cada associação.

Os neossolos litólicos $(33,44 \%)$ e cambissolos háplicos $(27,74 \%)$ são predominantes (tabela 01 ), apesar da diminuição percentual se comparado ao mapa geral dos solos (figura 02) onde eles representavam $51,89 \%$ e $39,34 \%$ respectivamente, continuam sendo responsáveis por mais da metade da área da bacia. Por outro lado a área mapeada com argissolos aumentou de 8,77\% para $17,85 \%$ devido a discriminação das áreas onde o argissolo aparecia 
SOUZA, O.P. de. Catenas e detalhamento expedito dos solos da bacia do...

associado com um solo principal (cambissolo ou neossolo litólico). Tanto os afloramentos rochosos quanto os luvissolos crômicos e os planossolos representam por volta de $4 \%$ da área total da bacia. Por fim, foi identificada a porcentagem da área onde há a presença de lagos artificial ou natural o que equivale a $5,15 \%$ da bacia, da qual o Açude do Saco no centro da bacia representa $85 \%$ desse valor.

Tabela 1: Detalhamento da área das classes de solo em $\mathrm{Km}^{2}$ e a porcentagem do total

\begin{tabular}{lrr}
\hline UNIDADE & $\mathrm{Km}^{\mathbf{2}}$ & $\%$ \\
\hline Corpos d'água & 7.34 & $5.15 \%$ \\
\hline Afloramento Rochoso & 6.25 & $4.39 \%$ \\
\hline Argissolo Amarelo e Argissolo Vermelho-Amarelo & 6.18 & $4.34 \%$ \\
\hline Argissolo Vermelho & 5.69 & $3.99 \%$ \\
\hline Argissolo Vermelho-Amarelo & 10.94 & $7.67 \%$ \\
\hline Argissolo Vermelho-Amarelo e Argissolo Vermelho & 2.42 & $1.70 \%$ \\
\hline Argissolo Vermelho-Amarelo e Argissolo Vermelho e Cambissolo Háplico & 0.21 & $0.15 \%$ \\
\hline Cambissolo Háplico & 39.55 & $27.74 \%$ \\
\hline Gleissolo Háplico e Neossolo Flúvico & 2.18 & $1.53 \%$ \\
\hline Luvissolo Crômico & 5.96 & $4.18 \%$ \\
\hline Neossolo Litólico & 49.12 & $34.44 \%$ \\
\hline Planossolo Háplico & 0.14 & $0.10 \%$ \\
\hline Planossolo Nátrico e Planossolo Háplico & 6.61 & $4.64 \%$ \\
\hline TOTAL & 142.60 & $100.00 \%$ \\
\hline
\end{tabular}

A principal dificuldade no detalhamento da espacialização dos solos deu-se na associação Ce1, única associação obtida a partir do mapeamento de solos da Paraíba, o qual acabou gerando uma incoerência da descrição dessa associação. A incoerência é relativa a não especificação da proporção entre os solos, no caso cambissolo háplico e neossolo litólico. Deste modo, essa 
SOUZA, O.P. de. Catenas e detalhamento expedito dos solos da bacia do...

associação foi detalhada seguindo a porcentagem $60 \% / 40 \%$, de modo semelhante à associação R2.

Outra associação destoante das demais é a R18 a qual apresentou classes não presentes nas outras associações, mais especificamente duas variações não usuais semelhantes a outras classes da bacia; variações estas que apresentaram espacialização ínfima no contexto da bacia, menos de $0,15 \%$ para ambas as variações. A primeira foi a associação de Argissolo VermelhoAmarelo e Argissolo Vermelho e Cambissolo Háplico, onde em todos as outras associações os argissolos foram separados do cambissolo. E a segunda foi a presença do planossolo háplico isolado, enquanto que o normal nas outras associações foi a presença do planossolo háplico conjuntamente com o planossolo nátrico.

\section{Conclusões}

O detalhamento da espacialização das classes de solo é necessário para ser utilizado como dado base para trabalhos posteriores como para modelagens de escoamento superficial ou erosão de solos. Para tais trabalhos a resposta de uma área com afloramento rochoso ou neossolo litólico será completamente diferente de uma área com argissolos, por exemplo; o que não seria identificado ao utilizar o mapeamento geral das associações de solos, onde uma mesma associação apresenta solos com respostas dispares.

Deste modo, a metodologia utilizada, baseada nas catenas referências para o sertão pernambucano e nos parâmetros e diretrizes básicos do mapeamento digital de solos, foi eficaz na espacialização das classes de solo. Apenas as associações de solo onde diferentes tipos de solo estão inseridos em uma mesma classe, como a R18, não puderam ser completamente desmembradas para uma única classe de solo. Nesses casos é interessante levar em consideração que por vezes, como é no presente caso, a localidade em questão não apresenta características climáticas, litológicas 
SOUZA, O.P. de. Catenas e detalhamento expedito dos solos da bacia do...

e/ou geomorfológicas diferentes de suas áreas adjacentes e de ambientes semelhantes, o que não justificaria uma variação na associação de solos dessa área.

O software ArcGis 10.1 apresentou as ferramentas necessárias para a análise e demonstrou-se capaz do processamento dos dados para a delimitação célere e precisa (seguindo os parâmetros utilizados) das classes de solo. Além de ser um software de ampla divulgação e uso comum nas pesquisas/trabalhos ambientais.

As catenas definidas por Correa, Souza e Cavalcanti (em prelo), abarcaram adequadamente a variação paisagística das relações solo/relevo da área de estudo, mostrando-se adequada para a identificação de solos nos ambientes semiáridos nordestinos; em especial aqueles com litologia cristalina com predominância de granitos e metagranitoides.

O nível de detalhe dos dados ASTER GDEM 2 mostrou-se adequado para a definição dos elementos topográficos analisados; levando em consideração o objetivo principal do trabalho. A utilização de dados com menor precisão espacial como, por exemplo, SRTM, deve ser realizada com ressalvas e análise específicas sobre a qualidade das informações geradas a partir dos mesmos (declividade, acumulação de água e distância do leito). Por outro lado, a utilização de dados com melhor resolução espacial possibilitaria a inclusão de novos parâmetros utilizados no mapeamento digital de solos, tal como a curvatura das encostas.

Por fim deve-se levar em conta o objetivo para qual se deseja uma distribuição mais detalhada das classes de solo, sendo que a metodologia aqui empregada adéqua-se a trabalhos onde o foco não é a pedologia, e sim a distribuição dos solos utilizada como base de dados para o trabalho principal. Deste modo, a presente metodologia mostrou-se célere e com precisão adequada para o detalhamento espacial das associações de solo de uma área representativa do sertão pernambucano. 
SOUZA, O.P. de. Catenas e detalhamento expedito dos solos da bacia do...

\section{Referências bibliográficas}

BETARD, F.; PEUlvaST, J. P.; SALES, V. C. Caracterização morfopedológica de uma serra úmida no semi-árido do Nordeste brasileiro: o caso do maciço de Baturité-CE. Mercator, v. 12, p. 107-126, 2007.

BODAGHABADI, M. B. et al. Using Canonical Correspondence Analysis (CCA) to identify the most important DEM attributes for digital soil mapping applications. Catena, v. 86, p. 66-74, 2011.

BRASIL, MINISTÉRIO DA AGRICULTURA. Levantamento Exploratório - Reconhecimento de Solos do Estado da Paraiba. Rio de Janeiro: Equipe de Pedologia e Fertilidade do Solo (MA), 1972.

BRUIN, S.; STEIN, A. Soil-landscape modelling using fuzzy cmeans clustering of attribute data derived from a Digital Elevation Model (DEM). Geoderma, n. 83, p. 17-33, 1998.

CAMPOS, M. C. C.; QUEIROZ, S. B. Reclassificação dos perfis descritos no Levantamento Exploratório-Reconhecimento de Solos do Estado da Paraíba. Revista de Biologia e Ciências da Terra, v. 3, n 1, $1^{\mathrm{o}}$ semestre, p. 45-50, 2006.

CARDENAS, G. C. et al. Computer-assisted cartography using topographic properties: precision and accuracy of local soil maps in Central Mexico. Revista Brasileira de Ciência dos Solos, v. 35, p. 682-691, 2011.

CHAGAS, C. S. et al. Integração de dados do QUICKBIRD e atributos do terreno no mapeamento digital de solos por redes neurais artificiais. Revista Brasileira de Ciências do Solo, n. 35, p. 693-204, 2011. 
SOUZA, O.P. de. Catenas e detalhamento expedito dos solos da bacia do... CORRÊA, A. C. B. et al. Megageomorfologia e morfoestrutura do Planalto da Borborema. Revista do Instituto Geológico, n. 31 (1/2), p. 35-52, 2012.

CORRÊA, A. C. B.; SOUZA, J. O. P.; CAVAlCANTI, L. C. S. Solos do ambiente semi-árido brasileiro: erosão e degradação a partir de uma perspectiva geomorfológica. [S.1.]: [s.n.], em prelo.

EMBRAPA - CENTRO NACIONAL DE PESQUISAS DE SOLOS. Sistema brasileiro de classificação de solos. $2^{\mathrm{a}}$. ed. Rio de Janeiro: EMBRAPA-SPI, 2006.

EMBRAPA. Zoneamento Agroecológico do Estado de Pernambuco - ZAPE. Recife: Embrapa Solos/Governo do Estado de Pernambuco - Secretaria de Produção Rural e Reforma Agrária, 2001. CD-ROM. (Embrapa Solos. Documentos, 35), 2001.

GIASSON, E. et al. Digital soil mapping using multiple logistic regression on terrain parameters in southern Brazil. Scientia Agricola, v. 63 n.3, p. 262-268, 2006.

IPPOLITI, G. A. et al. Análise digital do terreno: ferramenta na identificação de pedoformas em microbacia na região de "mar de morros" (MG). Revista Brasileira de Ciências do Solo, n. 29, p. 269-276, 2005.

MULDER, V. L. et al. The uso of remote sensing in soil and terrain mapping - A review. Geoderma, n. 162, p. 1-19, 2011.

NANNI, M. R. et al. Discriminação de unidades de paisagem para fins de levantamentos pedológicos por meio da resposta espectral orbital. Acta Scientiarum. Agronomy, v. 32 n.3, p. 555-561, 2010 . 
SOUZA, O.P. de. Catenas e detalhamento expedito dos solos da bacia do...

SCULL, P. et al. Predictive soil mapping: a review. Progress in Physical Geography, v. 27,2, p. 171-197, 2003.

VALLEJO, A. M. et al. Small scale digital soil mapping in Southestern Kenya. Catena, n. 76, p. 44-53, 2008.

ZIADAT, F. M. Land suitability classification using different sources of information: Soil maps and predicted soil attributes in Jordan. Geoderma, v. 140, p. 73-80, 2007.

ZIADAT, F. M.; TAYLOR, J. C.; BREWER, T. R. Merging Landsat TM imagery with topographic data to aid soil mapping in the Badia region of Jordan. Journal of Arid Environments, n. 54, p. 527-541, 2003.

Recebido em junho de 2013 Aceito em novembro de 2013 